\title{
Caracterização de quintais e aspectos socioeconômicos de moradores que cultivam plantas medicinais em um assentamento rural
}

\author{
Characterization of backyards and socioeconomic aspects of residents who grow medicinal plants
}

in a rural settlement

Caracterización de patios traseros y aspectos socioeconómicos de residentes que cultivan plantas medicinales en un asentamiento rural

\section{Resumo}

$\mathrm{Na}$ zona rural, como em assentamentos na região amazônica brasileira, agricultores familiares cultivam plantas medicinais em seus quintais como uma opção frente à deficiência no atendimento de adequados serviços de saúde e medicamentos necessários, em busca de benefícios para a alimentação e saúde. A partir desse contexto, objetivou-se realizar a caracterização de quintais e do perfil socioeconômico de moradores do assentamento São Francisco, em Canutama - AM, com a finalidade de verificar a realidade local. Trata-se de uma pesquisa com caráter descritivo, sob o uso de abordagem qualitativa e quantitativa. Para o levantamento de dados primários, foram realizadas entrevistas semiestruturadas com 32 moradores, sendo utilizada a técnica "bola de neve". Foram obtidos 238 registros de plantas medicinais encontradas nos quintais, sendo que às mulheres são atribuídas 137 citações, enquanto que aos homens, 101 citações, cabendo às mulheres e aos idosos a responsabilidade pela manutenção. Apesar de lacunas socioeconômicas, os entrevistados procuram cultivar plantas medicinais em seus quintais com base em experiências, saberes e características físicas da região. No entanto, é preciso atenção quanto à legitimidade, acesso e atuação efetiva de políticas públicas, ademais, à disponibilização e eficiência de assistência técnica, sobretudo na região amazônica, cujo conhecimento sobre os elementos da natureza e sua dinâmica é utilizado como recurso de sobrevivência, podendo ser visto como uma nova forma de encarar a relação do homem com a natureza, aplicando estratégias de uso sustentável em políticas públicas de saúde.

Palavras-chave: Agricultores familiares; Flora medicinal; Meio rural; Região Norte.

\begin{abstract}
In rural areas, as in settlements in the Brazilian Amazon region, family farmers grow medicinal plants in their backyards as an option in view of the deficiency in providing adequate health services and necessary medicines, in search of benefits for food and health. From this context, the objective was to characterize backyards and the socioeconomic profile of residents of the São Francisco settlement, in Canutama - AM, in order to verify the local reality. It is a descriptive research, using a qualitative and quantitative approach. For the survey of primary data, semistructured interviews were conducted with 32 residents, using the "snowball" technique. 238 records of medicinal plants found in backyards were obtained, with women receiving 137 citations, while men received 101 citations, with women and the elderly being responsible for maintenance. Despite socioeconomic gaps, respondents seek to grow medicinal plants in their backyards based on experiences, knowledge and physical characteristics of the region. However, attention is needed regarding the legitimacy, access and effective performance of public policies, in addition to the availability and efficiency of technical assistance, especially in the Amazon region, whose knowledge about the elements of nature and its dynamics is used as survival resource, which can be seen as a new way of facing the relationship between man and nature, applying sustainable use strategies in public health policies.
\end{abstract}

Keywords: Family farmers; Medicinal flora; Countryside; North Region. 


\begin{abstract}
Resumen
En las zonas rurales, como en los asentamientos de la Amazonía brasileña, los agricultores familiares cultivan plantas medicinales en sus patios traseros como una opción ante su deficiencia en la prestación de los servicios de salud adecuados y los medicamentos necesarios, en busca de beneficios para la alimentación y la salud. Desde este contexto, el objetivo fue realizar la caracterización de los patios traseros y del perfil socioeconómico de los vecinos del asentamiento São Francisco, en Canutama - AM, con el fin de verificar la realidad local. Se trata de una investigación descriptiva, con un enfoque cualitativo y cuantitativo. Para la recolección de datos primarios se realizaron entrevistas semiestructuradas a 32 residentes, utilizando la técnica de "bola de nieve". Se obtuvieron un total de 238 registros de plantas medicinales encontradas en patios traseros; las mujeres recibieron 137 citaciones, mientras que los hombres recibieron 101 citaciones, siendo las mujeres y los ancianos los responsables del mantenimiento. A pesar de las brechas socioeconómicas, los encuestados buscan cultivar plantas medicinales en sus patios traseros basándose en experiencias, conocimientos y características físicas de la región. Sin embargo, es necesario prestar atención a la legitimidad, acceso y acción efectiva de las políticas públicas, además de la disponibilidad y eficiencia de la asistencia técnica, especialmente en la región amazónica, cuyo conocimiento sobre los elementos de la naturaleza y su dinámica se utiliza como recurso de supervivencia, lo que puede verse como una nueva forma de enfrentar la relación entre el hombre y la naturaleza, aplicando estrategias de uso sostenible en las políticas de salud pública.
\end{abstract}

Palabras clave: Agricultores familiares; Flora medicinal; Campo; Región del Norte.

\title{
1. Introdução
}

No Brasil, produtos de origem natural, em especial, plantas medicinais, são vistos pela maior parte da população como a única fonte para a cura, alívio e/ou tratamentos de doenças (Messias et al., 2015). Na zona rural brasileira, trabalhadores utilizam plantas medicinais como uma alternativa diante da ausência de acesso aos serviços adequados de saúde e medicamentos necessários (Ricardo, 2011).

Segundo Lima et al. (2020), a Região Norte do país não se torna uma exceção, a qual faz uso de espécies vegetais medicinais, visando ao aproveitamento de seu potencial químico com benefícios para a saúde e alimentação. Pode-se depreender esse contexto nos assentamentos, como em trabalhos de Lima et al. (2015), Leandro et al. (2017) e Silva et al. (2020).

$\mathrm{O}$ assentamento rural detém beneficiários diretos, pertencentes à agricultura familiar, e indiretos. Os agricultores familiares, incluindo assentamentos rurais, vêm exercendo um papel fundamental na área agrícola nacional. À vista disso, salienta-se a necessidade de pesquisas que realizem a caracterização desse grupo social (Moraes \& Sant'ana, 2016).

$\mathrm{Na}$ Amazônia brasileira, agricultores familiares realizam atividades produtivas que servem como fonte de renda e contribuem para a sobrevivência deles e de sua família. Para esse segmento, o Estado deve promover políticas públicas e ações voltadas para a defesa de seus direitos alusivos à cidadania, de forma que continue a realizar práticas tradicionais atendendo a princípios de dignidade humana, concomitantemente, auxiliar na conservação de recursos naturais da região amazônica (Lima \& Pontes Filho, 2020).

O conceito de assentamento relaciona-se ao processo de reforma agrária, com o intuito de levar em consideração a vida dos assentados por se encontrarem na floresta amazônica, incluindo os aspectos ambiental e socioeconômico, os quais estão associados. Então, não se trata somente de uma unidade agrícola com um limite territorial. Deve-se apresentar planejamento voltado para a questão social, sob intervenção da relação homem-natureza, de modo sustentável. Além de abarcar políticas de assistência técnica e âmbito de desenvolvimento rural (Barbosa, 2019).

Em relação à inserção das plantas medicinais e fitoterápicos, no ano de 2006, foram aprovadas duas políticas públicas para facilitar a integração da medicina tradicional no sistema nacional de atenção à saúde. Essas políticas consistiram em: Política Nacional de Práticas Integrativas e Complementares, para normatizar e sistematizar a inclusão das plantas medicinais e da fitoterapia nos serviços e nas práticas de saúde; e a Política Nacional de Plantas Medicinais e Fitoterápicos, com o objetivo de buscar a garantia do acesso mais seguro e o uso racional das plantas medicinais, promovendo o uso sustentável da 
biodiversidade e também ampliando as opções terapêuticas aos usuários do Sistema Único de Saúde (SUS) (Schiavo et al., 2017).

No processo de uso sustentável da biodiversidade amazônica, o quintal é considerado uma das formas mais antigas de manejo da terra, o termo é utilizado para se referir ao terreno situado ao redor da casa, definido, na maioria das vezes, como a porção de terra próxima à residência, de acesso fácil e cômodo, na qual se cultivam ou se mantêm múltiplas espécies que fornecem parte das necessidades nutricionais da família, bem como outros produtos, como lenha e plantas medicinais (Amaral \& Guarim Neto, 2008). Nesta perspectiva, o levantamento de variáveis socioeconômicas é fundamental para análise desse conhecimento, pois o uso de plantas medicinais é ressaltado em função da deficiência de acesso ao atendimento médico local, podendo ser entendido por meio da busca por práticas alternativas (curandeiras e rezadeiras) perante a insatisfação com os serviços de saúde públicos (ou privados) e, até mesmo, decorrente do descrédito na medicina (Gomes \& Lima, 2017; Medeiros et al., 2018; Barreto et al., 2020).

Em face do exposto, objetivou-se caracterizar os quintais e o perfil socioeconômico de moradores do assentamento São Francisco, no município de Canutama, estado do Amazonas, com o propósito de verificar a realidade local vivenciada por eles ao realizarem o cultivo de espécies com finalidade terapêutica.

\section{Metodologia}

\section{1 Área de estudo}

O município de Canutama situa-se na Região Sul do estado do Amazonas e na microrregião do Purus, fazendo fronteira a norte com Tapauá, a leste com Humaitá, a oeste com Lábrea e a sul com Porto Velho (Meirelles et al., 2018). De acordo com dados do Censo de 2010 (IBGE, 2017a), abrange 12.738 habitantes. Conforme esse Censo, apresenta uma população rural de 6.056 moradores, cerca de $47,5 \%$ do total de residentes, o que retrata ampla presença humana no meio rural (Nogueira et al., 2017).

O solo na região foi classificado como argissolo vermelho-amarelo situado na Planície Amazônica entre os rios Madeira e Purus (EMBRAPA, 2013). A temperatura no município é, em média, $26^{\circ} \mathrm{C}$ e o clima é caracterizado como tropical chuvoso-úmido (IDAM, 2013).

O Projeto de Assentamento (PA) São Francisco está localizado no sul de Canutama (NUPEAS, 2016). O assentamento contém extensão de 18.120 ha, dividido em sete vicinais, possuindo capacidade para 298 unidades agrícolas e, por conseguinte, 298 famílias. É regulamentado pela Resolução n 19 de 29 de abril de 1993 e, em 1995, houve o início de seu processo de ocupação (INCRA, 2017; Souza et al., 2018). Abarca 255 famílias assentadas, mediante dados do INCRA (2020). No entanto, muitas casas encontravam-se fechadas, em virtude de alguns assentados não residirem de forma definitiva na área de estudo.

Ainda que apresente um posto de endemias (FUNASA), não foram encontrados profissionais de saúde (Souza et al., 2018) e, consequentemente, o posto está sem funcionamento. Somente duas escolas com Ensino Fundamental regular estão funcionando (Barbosa, 2019).

Segundo Carvalho (2019), para a administração, organização e apoio às dificuldades encontradas pelos agricultores com respeito às práticas socioeconômicas, existem duas associações: Associação de Produtores Rurais de Guaraná, Açaí e Hortifrutigranjeiros de Canutama (APROGAH) e Associação dos Produtores Rurais Unidos do Colombo (APRUC).

$\mathrm{O}$ assentamento caracteriza-se pelo desenvolvimento de atividades do extrativismo e agricultura, com produção de culturas, como guaraná (Paullinia cupana Kunth) e cupuaçu (Theobroma grandiflorum (Willd. ex Spreng.) Schum), a qual é 
escoada pela BR-319 (Nogueira et al., 2017). Ocorre criação de gado em alguns lotes, o que denota existência de atividade pecuarista. Outros animais, como porcos, perus e galinhas, podem ser encontrados na localidade (Carvalho, 2019).

\subsection{Levantamento e análise de dados}

A pesquisa adquiriu aprovação do Comitê de Ética em Pesquisa com seres humanos da Universidade Federal do Amazonas (CEP - UFAM), com o número de parecer 2.914.108. Trata-se de uma pesquisa de levantamento, apresenta caráter descritivo, com abordagem qualitativa e quantitativa (Prodanov \& Freitas, 2013). A amostragem configurou-se em nãoprobabilística intencional. Foi utilizada a técnica "bola de neve" ("Snow ball”) (Bailey, 1994), na qual a partir do contato inicial com a comunidade, um primeiro informante indicou outros assentados, e, assim, sucessivamente.

Para a participação na pesquisa, foram utilizados os seguintes critérios de inclusão: ser maior de idade, que realize o cultivo, faça uso de plantas medicinais e apresente amplo conhecimento sobre elas em seus quintais.

$\mathrm{O}$ assentamento conta com quatro linhas ou ramais, isto é, pequenas estradas que permitem chegar às casas. A pesquisa foi desenvolvida nas proximidades das linhas 2 (Vicinal Colombo) e 3 (Vicinal Jacy), conforme visualizado na Figura 1, dado que havia a impossibilidade de acesso às linhas 1 e 4 no período de coleta de dados, correspondente aos meses de agosto de 2018 a janeiro de 2019.

Como instrumento de coleta de dados primários, foram aplicadas 32 entrevistas semiestruturadas, e fez-se uso de formulários com questões abertas e fechadas. Realizaram-se visitas in loco aos lotes, de forma que não atrapalhasse o entrevistado em suas atividades e possibilitasse o desenvolvimento das entrevistas sem frequentes interrupções.

Figura 1. Localização dos quintais no PA São Francisco, Canutama, Amazonas, Brasil.

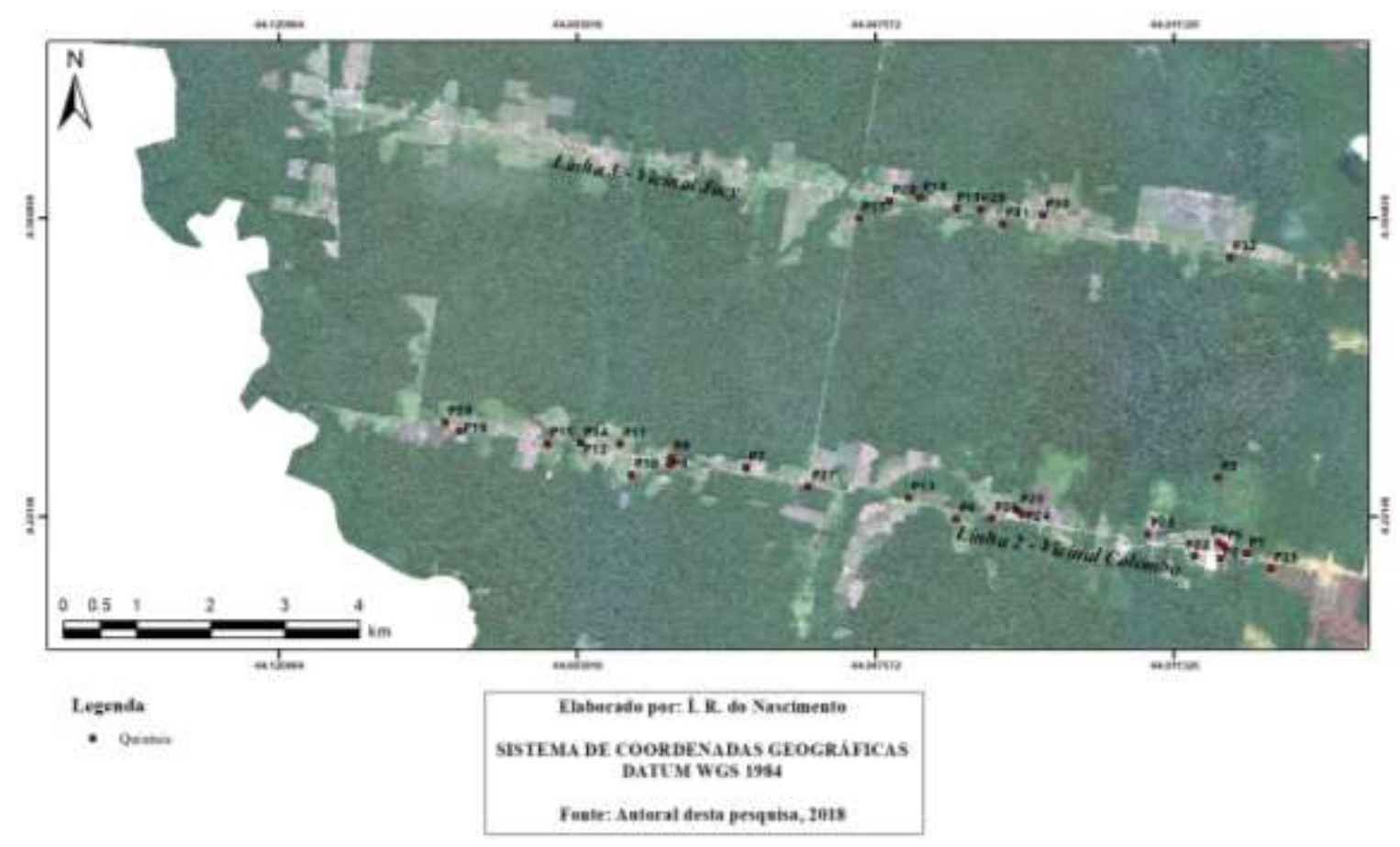

Fonte: Autores.

Durante as entrevistas foram obtidas informações sobre o perfil socioeconômico dos moradores, além de dados relativos aos quintais. 
Para a análise dos dados utilizou-se o programa Excel versão 2019 para Windows, sendo aplicada a estatística descritiva, com a realização da distribuição de porcentagens (frequência relativa). De acordo com Marconi e Lakatos (1996), a finalidade desse ramo da estatística é representar de modo sintético, conciso e compreensível as informações incluídas em um conjunto de dados.

\section{Resultados e Discussão}

\subsection{Caracterização dos quintais}

O quintal pode apresentar características sociais e culturais peculiares de um determinado grupo, de forma a abranger organização, diferentes finalidades de plantas presentes e práticas de manejo, considerando influências socioculturais adquiridas e experenciadas no decorrer do tempo. Configura-se em um espaço no qual famílias abarcam uma riqueza florística, como plantas medicinais, e, até mesmo, faunística, promovendo a consolidação de relações interpessoais, conservação de costumes e tradições que estão vinculados ao uso e cuidado da agrobiodiversidade (Maia \& Bombarda Sobrinho, 2019; Rayol \& Miranda, 2019). Na Tabela 1, estão dispostos dados relativos ao tempo de existência, área e responsabilidade pela manutenção dos quintais com as respectivas frequências.

Tabela 1. Tempo de existência, área e responsabilidade pela manutenção dos quintais.

\begin{tabular}{|c|c|}
\hline Dados & $\%$ \\
\hline \multicolumn{2}{|l|}{ Tempo } \\
\hline Menos de 5 anos & 19 \\
\hline $5-10$ anos & 31 \\
\hline $11-16$ anos & 22 \\
\hline $17-21$ anos & 28 \\
\hline \multicolumn{2}{|l|}{ Área $\left(\mathbf{m}^{2}\right)$} \\
\hline $1000-5000$ & 34,38 \\
\hline $6000-10000$ & 21,88 \\
\hline $11000-20000$ & 6,25 \\
\hline 60000 & 3,13 \\
\hline 600000 & 34,38 \\
\hline \multicolumn{2}{|l|}{ Responsável pela manutenção } \\
\hline Entrevistada & 28 \\
\hline Entrevistada e marido & 16 \\
\hline Entrevistada, filho e neto & 3 \\
\hline Entrevistada, marido e filhos & 3 \\
\hline Entrevistado & 22 \\
\hline Entrevistado e esposa & 13 \\
\hline Esposa e filho & 3 \\
\hline Marido & 9 \\
\hline Tia & 3 \\
\hline
\end{tabular}

Fonte: Dados da pesquisa.

No que tange ao tempo de existência do quintal, houve variação, prevalecendo entre cinco e 10 anos. Em concordância com Vieira et al. (2012), a idade dos quintais é uma das circunstâncias que resultam na diversidade de plantas.

Observaram-se diferentes áreas, sendo que 34,4\% não especificaram a área correspondente do quintal de sua casa, em virtude de não souberem, relatando, desse modo, a do lote, isto é, $600000 \mathrm{~m}^{2}$. Em referência à variação espacial dos quintais observada, pesquisas retratam que não se considera um padrão de formato e tamanho, havendo o registro de diferentes estruturas (Santos et al., 2019). 
A responsabilidade da manutenção dos quintais cabe, com ênfase, pelas mulheres. A manutenção dos quintais assumida, majoritariamente, pelo gênero feminino, também foi constatada por Pereira et al. (2018), em que os autores complementam afirmando que as mulheres colaboram para a saúde familiar, autossuficiência alimentar, renda e ampliação da diversidade biológica do quintal.

Ao considerar um total de 238 citações de plantas medicinais, às mulheres foram atribuídas 137 citações, enquanto que aos homens, 101 citações, com destaque também aos mais velhos na manutenção.

Com base nesses resultados, presume-se o predomínio do etnoconhecimento feminino no tocante ao cultivo de plantas medicinais nos quintais caseiros do assentamento, como retrata uma moradora: "Gosto muito de plantas.", a qual expressa o desejo constante de cultivar espécies medicinais em seu quintal. As mulheres exercem atividades domésticas próximas aos quintais e, consequentemente, possuem maior acesso e utilização.

Em face a essa linha de interpretação, Leal et al. (2020) realçam que as mulheres, são responsáveis, além dos afazeres do lar, pelo espaço ao redor da casa, o qual inclui a manutenção dos quintais, nos quais verifica-se a produção de ervas medicinais e hortaliças, entre outras espécies vegetais. Os quintais são vistos como locais agroecológicos, ao passo que neles são aplicados, como exemplo, conhecimentos tradicionais sobre o manejo. As mulheres, ao desempenharem atividades da agricultura, possuem predominância dos saberes relacionados às plantas, técnicas de plantios e sementes, exercendo a responsabilidade pela difusão de conhecimentos para as próximas gerações e possibilitando a conservação e valorização da cultura na localidade.

Na percepção de Gomes et al. (2019), o papel feminino, em assentamentos, também demonstra relevância no processo de disseminação dos saberes relativos a um meio ambiente sustentável.

Foi questionado se os moradores utilizam adubo e/ou outro material (ferramenta ou produto químico) no manejo das plantas e, em caso afirmativo, qual seria, resultando em 96 citações. Conforme o relato dos entrevistados, destacou-se o adubo orgânico (19,79\%), por meio da produção desse adubo um morador faz uso do processo de compostagem. Sequencialmente, teve-se a enxada (16,67\%); roçadeira (7,29\%); pá (6,25\%); boca de lobo $(5,21 \%)$; foice $(4,17 \%)$; adubo químico $(4,17 \%)$; calcário, cavadeira, enxadão, motosserra e veneno (3,13\% cada). É válido mencionar que 3,13\% não utilizam material.

Também são utilizados facão, machado, tesoura de poda e terras pretas de índio, as quais são, consoante Pessoa Junior et al. (2012, p. 1), “manchas de solo encontradas em toda a bacia Amazônica, em cuja origem está relacionada à deposição de restos de materiais de populações pré-colombianas", cada qual correspondendo a 2,08\%. Babaçu, balaio, o qual é um cesto de palha, cal, ciscador, garfo, palha de guaraná, plantadeira manual, pó de serra, que consiste em um resíduo proveniente do corte de madeira, e solo ácido obtiveram uma citação cada (1,04\%, respectivamente).

Conforme visto anteriormente, grande parte dos moradores utiliza adubo orgânico, o qual constitui-se em material vegetal ou animal, como por exemplo, esterco, restos vegetais e cascas, para o cultivo da flora medicinal. Finatto et al. (2013) salientam que o aproveitamento de resíduos orgânicos proporciona alta produtividade das culturas, mantém o solo fértil, melhorando suas propriedades químicas, biológicas e físicas, de modo a obter respostas positivas das plantas. Além disso, propicia o uso ecológico e sustentável, não provocando danos ao meio ambiente. Em consonância com dados do Censo Agropecuário, a parcela majoritária dos produtores rurais de Canutama - AM, correspondendo a 80 estabelecimentos agropecuários, faz uso de adubo orgânico, sem a aplicação de adubação química (IBGE, 2017b).

Ao serem questionados se seguem algum critério para a seleção de plantas a serem cultivadas, 63\% responderam que não possuem critério, apenas plantam para atender às suas necessidades, dentre os quais, um morador retratou que não recebe ajuda por parte do INCRA quanto ao fornecimento de mudas, ressaltando que "o projeto está parado" e outro expressou sua preocupação sobre a inoperância de assistência técnica para melhor auxiliá-lo no processo de cultivo. Entre os moradores que fazem uso de determinado critério, observaram-se determinados relatos, como: 
"Depende da época e do solo." (Residente feminino, 32 anos)

"Planta que traz benefício." (Residente masculino, 52 anos)

"Escolho as que estão adaptadas à região, como o açaí." (Residente masculino, 54 anos).

A não ocorrência de assistência técnica sob responsabilidade de órgãos competentes é uma questão de preocupação por parte de alguns moradores, o que possibilita falta de informações necessárias e equipamentos adequados para a realização correta do cultivo. Um morador fez o seguinte desabafo: "Estamos esquecidos pelos órgãos competentes. Não tem como comprar uma máquina.". Em pesquisa realizada pelo Censo Agropecuário, de 1029 estabelecimentos pertencentes a produtores rurais no município de Canutama - AM, 949 não apresentam assistência técnica (IBGE, 2017b).

Frente a essa realidade, Gomes et al. (2018b) afirmam que, embora os agricultores familiares do assentamento possuam perfil para obterem apoio do Programa Nacional de Assistência Técnica e Extensão Rural - PNATER, não são contemplados, uma vez que nem todos ainda têm acesso à essa política.

Barbosa (2019) evidencia em sua pesquisa, no que se refere às políticas públicas no assentamento deste estudo, o relato dos moradores ao salientarem que ainda é necessária a visita técnica especializada para a correção no solo, adicionando calcário, do mesmo modo que aragem dos terrenos com o emprego de maquinários pelas instituições governamentais ou, até mesmo, associação própria. Entretanto, em concordância com o autor, o apoio técnico especializado vai de encontro à falta de logística e técnicos, tanto quanto a burocracia administrativa, ao passo que não há veículos para trafegar nas vicinais, as quais não se encontram em bom estado, sobretudo, na época chuvosa. O que prejudica o acompanhamento de técnicos, remetendo à dependência de um aparato logístico para parcerias com órgãos competentes, orientações e assessorias especializadas, e o tão esperado suporte para a agricultura familiar.

Carvalho et al. (2009) evidenciam que a prioridade da assistência técnica é o uso de técnicas conservacionistas, com a finalidade de, entre outras atividades, proteger os recursos naturais e, ao serem implantados sistemas produtivos, promover a sustentabilidade econômica e socioambiental no decorrer do tempo. Contudo, como foi dito anteriormente, a assistência técnica não acontece.

Questionou-se a existência de alguma área preferencial do quintal para o cultivo de determinadas plantas. Em vista disso, $47 \%$ afirmaram que não possuem; 22\% disseram que preferem ao lado da casa; $13 \%$ retrataram atrás da casa. As demais respostas correspondem à roça; na frente e atrás da casa; na frente da casa; viveiro 50\%, esse com o propósito de receber raios solares de forma parcial; lugar onde não tem cascalho; e espaço no qual os animais não possam comer (3\%, respectivamente). Com base nisso, observou-se que as plantas medicinais, em grande parte, são cultivadas ao redor da casa em decorrência da facilidade de acesso, razão também verificada por Ferreira et al. (2016), no entanto, ressaltam em seu estudo que as plantas com finalidade terapêutica são selecionadas para serem cultivadas na parte de trás dos quintais.

Ao tratar-se acerca dos procedimentos para com as plantas que crescem espontaneamente, $56 \%$ dos interlocutores deixam crescer; $19 \%$ cortam; $13 \%$ realizam a poda, retirando parte das plantas; $6 \%$ cortam, completamente, certas espécies vegetais e deixam crescer outras e $6 \%$ mudam de lugar. O que indica o almejo da maioria dos interlocutores em conservar as espécies nativas e espontâneas, favorecendo a manutenção da biota local.

No que concerne às respostas referentes à origem das sementes ou mudas (Tabela 2), predominantemente, os informantes declararam que adquirem de vizinhos, sobressaindo, também, os que as obtêm da própria casa. 
Tabela 2. Origem das sementes/mudas.

\begin{tabular}{cc}
\hline Origem & $\%$ \\
\hline Vizinhos & 28,95 \\
Própria casa & 26,32 \\
Casa do Agricultor (Porto Velho - RO) & 7,89 \\
Moradores do assentamento & 7,89 \\
Porto Velho & 7,89 \\
Empresa Brasileira de Pesquisa Agropecuária - EMBRAPA (Porto Velho - & 5,26 \\
RO) & 2,63 \\
Cabixi e Machadinho - RO & 2,63 \\
Instituto de Desenvolvimento Agropecuário e Florestal Sustentável do & 2,63 \\
Estado do Amazonas - IDAM (Humaitá - AM) & 2,63 \\
Plantas espontâneas & 2,63 \\
Região próxima de Humaitá & 2,63 \\
Sogra & Viveiro entre Porto Velho e Candeias - RO
\end{tabular}

Fonte: Dados da pesquisa.

Diante dos resultados apresentados na tabela, a maior parte realiza a troca de mudas e sementes entre os vizinhos, ou seja, tem-se o compartilhamento, o qual contribui para a disseminação do saber popular e uso de diferentes plantas. Mas também, destacou-se a produção tradicional de suas próprias mudas com as sementes das espécies que estão situadas em seus quintais. Na concepção de Santos et al. (2018), os quintais são visualizados, inclusive, como espaços de socialização com a vizinhança, promovendo troca de material genético e saberes, por meio da doação de sementes e mudas, a qual consiste em uma prática frequente entre agricultores familiares, principalmente, realizada por mulheres.

Considerando 240 citações obtidas concernentes às técnicas de cultivo, 23,8\% condiz com a produção de muda, na qual enche-se uma "sacolinha" com solo adubado com matéria orgânica (contendo, por exemplo, pau, esterco de boi e galinha) e nela coloca-se semente, posteriormente, faz-se uma cova no solo e a põe. Em seguida, a cova é coberta com o solo retirado e compactada. O uso de baixo nível de tecnologia, isto é, poucas técnicas, foi certificado nos quintais, como averiguado por Almeida e Gama (2014), em quintais agroflorestais de um projeto de assentamento no município de Santarém, Pará.

Um morador, bastante conhecido no assentamento, procura realizar o manejo sustentável de espécies, como guaraná, em seu lote, cujo escopo é cultivar mudas com sementes, inserindo adubo orgânico, sem emprego de fertilizantes químicos (adubação química) e agrotóxicos que possam prejudicar a qualidade do solo e o desenvolvimento satisfatório de plantas herbáceas, arbustivas e arbóreas, além de alterar as propriedades fitoterápicas das espécies medicinais. Nessa perspectiva, Lima et al. (2020) enfatizam que todos os cidadãos têm como princípio e dever promover a proteção da vegetação de forma sustentável e racional, com vistas para o equilíbrio ambiental na Terra.

\subsection{Perfil socioeconômico}

Descrever o perfil socioeconômico torna-se inescusável, uma vez que fatores como gênero, idade, ocupação, origem e grau de instrução podem influenciar no conhecimento de uma população local acerca das plantas, conforme discorrem Albuquerque et al. (2010). Na Tabela 3, encontram-se determinadas características sociais observadas após as entrevistas. 
Tabela 3. Características sociais dos entrevistados no assentamento São Francisco, Canutama, Amazonas, Brasil.

\begin{tabular}{|c|c|}
\hline Características & $\%$ \\
\hline \multicolumn{2}{|l|}{ Gênero } \\
\hline Feminino & 59,4 \\
\hline Masculino & 40,6 \\
\hline \multicolumn{2}{|l|}{ Cor ou raça } \\
\hline Parda & 68,75 \\
\hline Negra & 18,75 \\
\hline Branca & 12,50 \\
\hline \multicolumn{2}{|l|}{ Religião } \\
\hline Evangélica & 56 \\
\hline Católica & 38 \\
\hline Nenhuma & 6 \\
\hline \multicolumn{2}{|l|}{ Faixa etária } \\
\hline $21-40$ & 19 \\
\hline $41-60$ & 59 \\
\hline $61-80$ & 22 \\
\hline \multicolumn{2}{|l|}{ Estado civil } \\
\hline Casado & 63 \\
\hline Solteiro & 25 \\
\hline Viúva & 9 \\
\hline União estável & 3 \\
\hline \multicolumn{2}{|l|}{ Tempo de residência } \\
\hline Menos de 10 anos & 31 \\
\hline 10 a 20 anos & 44 \\
\hline Mais de 20 anos & 25 \\
\hline \multicolumn{2}{|l|}{ Nível de escolaridade } \\
\hline Ensino Fundamental incompleto & 66 \\
\hline Ensino Médio incompleto & 13 \\
\hline Ensino Médio completo & 9 \\
\hline Ensino Superior incompleto & 6 \\
\hline Analfabetos & 6 \\
\hline
\end{tabular}

Fonte: Dados da pesquisa.

De acordo com a tabela, a maior parte dos entrevistados foi constituída por mulheres, haja vista que apresentam significativo conhecimento acerca das plantas medicinais, corroborando a observação feita por Silva et al. (2020) e Vásquez et al. (2014), os quais ainda destacam que elas assumem a responsabilidade no preparo de remédios caseiros e nos cuidados com a saúde dos familiares. Enquanto que em trabalho desenvolvido por Leandro et al. (2017) com relação à utilização de espécies medicinais no Projeto de Desenvolvimento Sustentável Virola-Jatobá, no município de Anapu, estado do Pará, sobressaiu-se o gênero masculino.

O caso de haver preponderância de entrevistados que se autodeclararam pardos corrobora o resultado encontrado por Araújo (2017), no qual $43 \%$ dos agricultores se consideram pardos. O autor desenvolveu um trabalho relativo à percepção agroecológica de 28 agricultores familiares do assentamento São Francisco, em Canutama - AM. Consoante o Censo Agropecuário, grande parcela dos produtores rurais, no município de Canutama, se considera parda (IBGE, 2017b).

A faixa etária dos interlocutores, cuja maioria é evangélica, está entre 21 e 71 anos. A média de idade é 51 anos, tendo em vista que a maior parte dos entrevistados possui entre 41 e 60 anos, e nessa faixa foi reportada maior quantidade de espécies cultivadas nos quintais. Flor e Barbosa (2015), ao compararem a quantidade de plantas citadas com a idade dos entrevistados em sua pesquisa acerca do uso de plantas medicinais no distrito de Marudá - PA, constataram que as mulheres entre 64 e 87 anos apresentaram o maior número de citações, afirmando que os mais velhos têm conhecimento de ampla diversidade botânica, em função da acumulação do saber assimilado no decorrer dos anos. No que corresponde à faixa etária 
dos entrevistados, Pereira et al. (2018) encontraram resultado análogo, entre 21 e 72 anos, em quintais agroflorestais de Agrovila no município de Altamira, Pará.

No que tange ao estado civil, verificou-se que, de modo predominante, os residentes são casados. Situação semelhante foi encontrada por Freitas et al. (2012), em que a maioria dos entrevistados é casada. Os autores, ao realizarem um levantamento etnobotânico das espécies medicinais dos quintais do Sítio Cruz, no município de São Miguel, no Rio Grande do Norte, salientam que a situação de casado pode ser associada com maiores saberes acerca das plantas, tendo em vista que a presença dos filhos requer a procura por soluções imediatas e práticas para o tratamento e cura de enfermidades.

No que se refere ao tempo de residência, boa parte dos respondentes moram no assentamento entre 10 e 20 anos. Os entrevistados que citaram maior quantidade de plantas residem no PA São Francisco há mais de 15 anos. O número de espécies conhecidas pelos moradores e as formas de uso podem ser explicados pelo tempo de residência na localidade em questão. De forma geral, quando um grupo de pessoas reside há mais tempo em uma comunidade, passa a vivenciar maior contato com outros residentes, adquirindo, aos poucos, saberes daqueles com os quais se relacionaram. E, ainda, a interação com os recursos naturais de um determinado local também é maior, pelo fato de o entrevistado morar na região há um período prolongado de tempo (Spanholi \& Barreto, 2018).

Ao considerar o nível de escolaridade, a maior parcela dos assentados respondentes apresenta Ensino Fundamental incompleto. Esse resultado mostrou-se similar em trabalhos desenvolvidos por Araújo (2017), Leandro et al. (2017) e Silva et al. (2020), cuja maioria dos entrevistados possui Ensino Fundamental incompleto.

Ao ser observada a precariedade da infraestrutura de escolas, pode-se verificar também a ausência de meios eletrônicos e biblioteca, situação precária de energia elétrica, incluindo a falta de abastecimento correto de água e as más condições sanitárias do ambiente escolar. Aperfeiçoar e permitir o acesso à educação formal, garantido constitucionalmente, possibilita, adicionalmente, a introdução de novas tecnologias de forma fácil e rápida ou o aperfeiçoamento de tecnologias já utilizadas. Ademais, torna-se uma estratégia fundamental para despertar o interesse de jovens em comunidades rurais e, por conseguinte, para a agricultura familiar, representando, dessa forma, o conhecimento transmitido de pai para o filho (Gomes et al., 2018b).

Em relação aos entrevistados que têm Ensino Fundamental incompleto, 15 pertencem à faixa etária de 41 a 60 anos; cinco, de 61 a 80 anos; e um, de 21 a 40 anos. Mesmo com o baixo nível de escolaridade, tal questão não indica falta ou pouco conhecimento tradicional.

Nesse cenário, Elisabetsky (2002) retrata que a "ausência de instrução formal não é sinônimo de ausência de conhecimento". Ainda, de acordo com a autora, para a ciência o conhecimento tradicional torna-se de interesse quando se refere ao relato verbal de pessoas, muitas vezes, analfabetas, todavia, demonstram ser tão sagazes quanto alguns cientistas, no que diz respeito à observação de fenômenos biológicos. De forma complementar, Cunha e Bortolotto (2011) salientam em seu artigo, que, apesar da baixa escolaridade, os assentados acreditam ser relevante manter informações referentes ao conhecimento de plantas medicinais ao longo dos anos e para as gerações futuras.

Em referência à ocupação ou profissão exercida, 11 moradores são agricultores $(34,38 \%)$, em que três correspondem ao gênero feminino e 11 se identificam como donas de casa (34,38\%). Os demais são auxiliares de serviços gerais $(12,50 \%)$; donas de casa e agricultoras (6,25\%); motoristas (6,25\%); um entrevistado é aposentado $(3,13 \%)$ e uma moradora é dona de mercado $(3,13 \%)$. Diante disso, as ocupações que se destacaram estão voltadas para a agricultura familiar e atividades do lar. Outros trabalhos na Região Norte também foram desenvolvidos com agricultores, abordando o papel da mulher nos cuidados domésticos e com os filhos, além do cultivo e manejo de plantas nos quintais (Vásquez et al., 2014; Leandro et al., 2017; Azambuja et al., 2018). 
No tocante à naturalidade, 28,1\% dos residentes entrevistados nasceram no estado de Rondônia (Gráfico 1). Enquanto que $59 \%$ do total de informantes já moraram em outra comunidade na zona rural (comunidade de origem), especialmente, do estado de Rondônia, perfazendo 41\% (Gráfico 2). Embora os moradores apresentem diferentes origens (primeiros locais por onde passaram), a identidade com a terra propicia a sua união, de modo que haja acúmulo de informações, por meio da inserção de novos conhecimentos relativos aos recursos vegetais locais (Cunha \& Bortolotto, 2011).

Gráfico 1. Naturalidade dos residentes entrevistados.

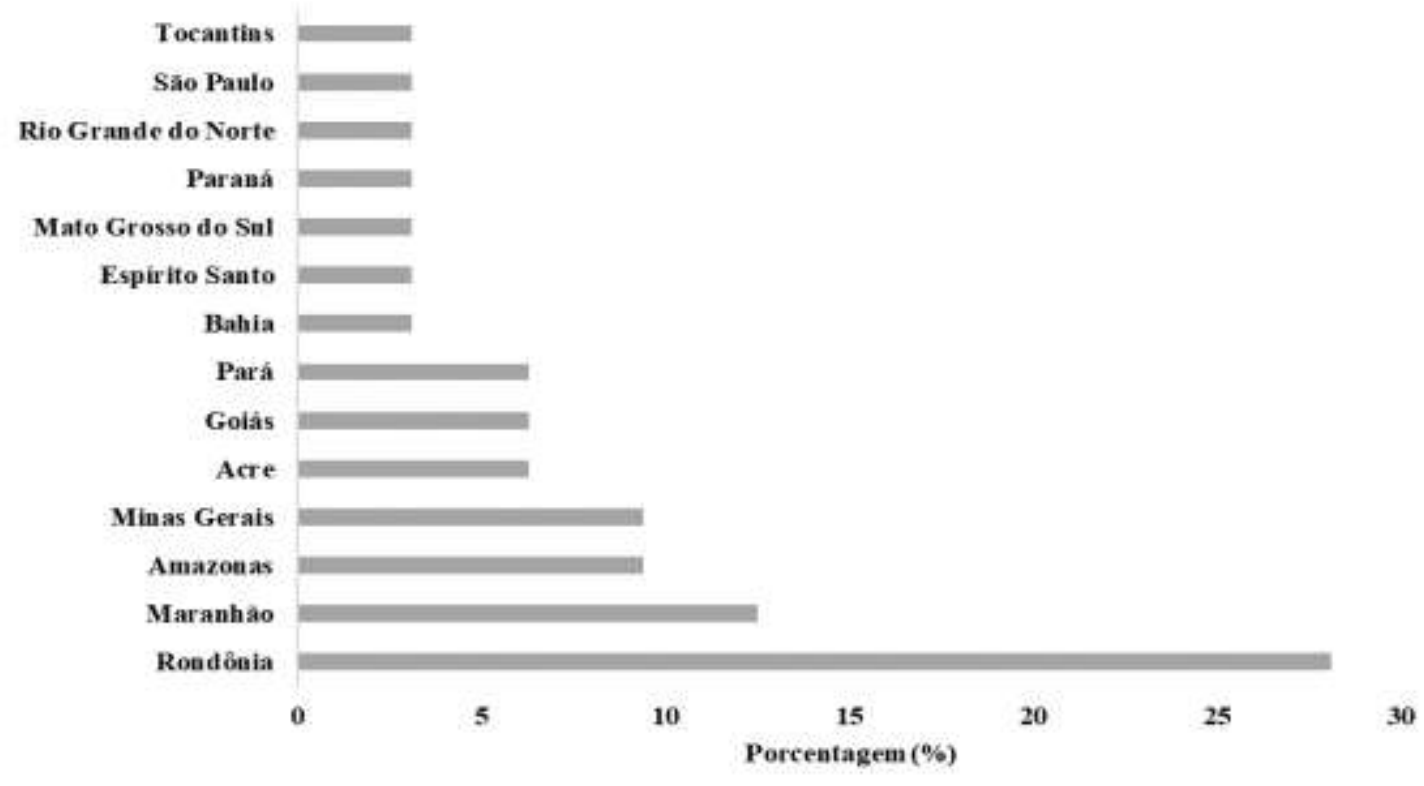

Fonte: Dados da pesquisa.

Gráfico 2. Origem dos moradores entrevistados.

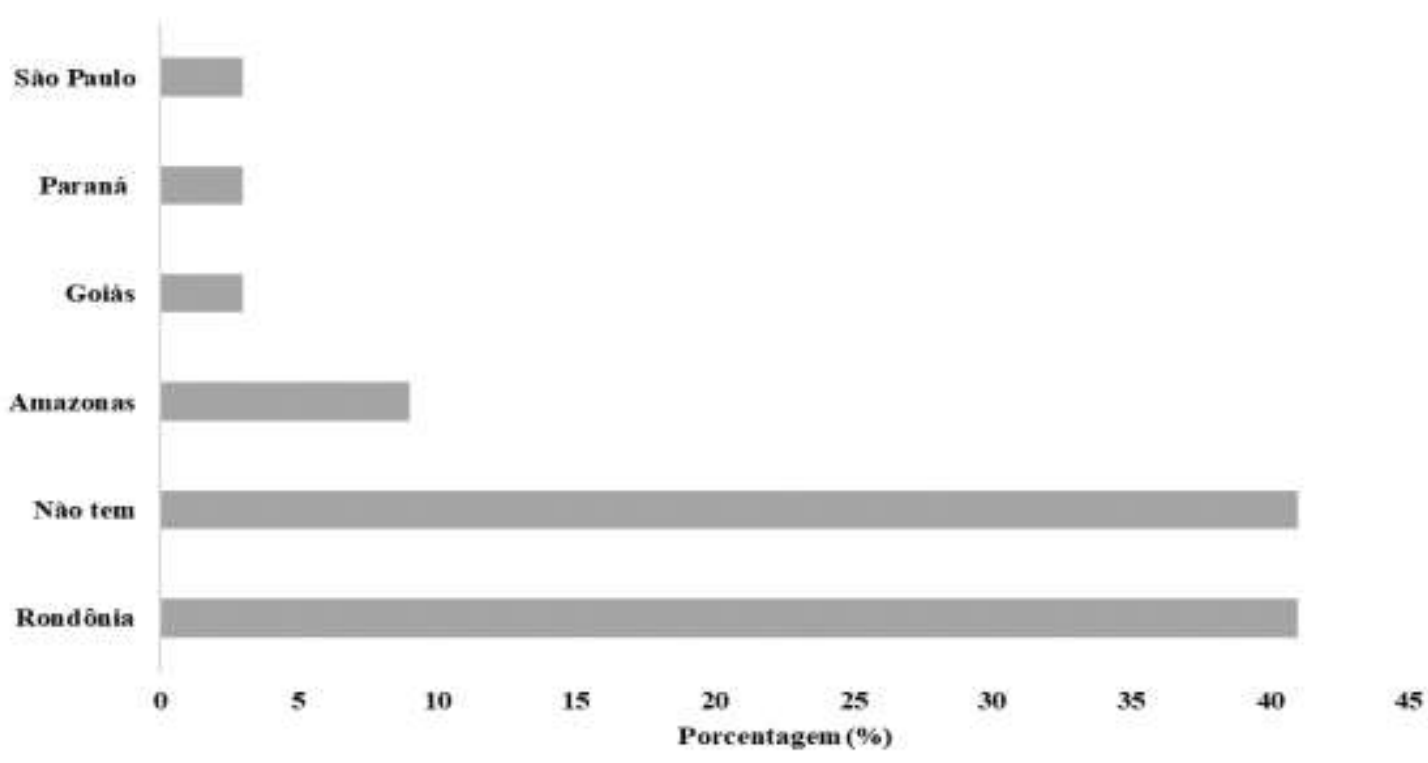

Fonte: Dados da pesquisa.

Os entrevistados também residiram em outros estados (Gráfico 3), cuja maior parte $(46,88 \%)$ em cidades do interior do estado de Rondônia. Os moradores se adaptaram à área do assentamento e realizam cultivo de plantas medicinais, conforme as condições socioeconômicas, de solo e temperatura. 
Nesse pensamento, Gomes et al. (2018b), que realizaram uma pesquisa relativa à assistência técnica e extensão rural em comunidades rurais do sul do Amazonas, ressaltam que apesar de grande parte dos agricultores serem provenientes de outras regiões do Brasil, se adequaram ao modo de produção e de vida dos agricultores familiares da região amazônica, segundo características culturais e ambientais da Amazônia. Indicando que a mudança do agricultor familiar consistiu, sobretudo, na procura por melhores condições de vida, fazendo-o participar do processo de ocupação do local em questão.

Gráfico 3. Estados em que os informantes moraram.

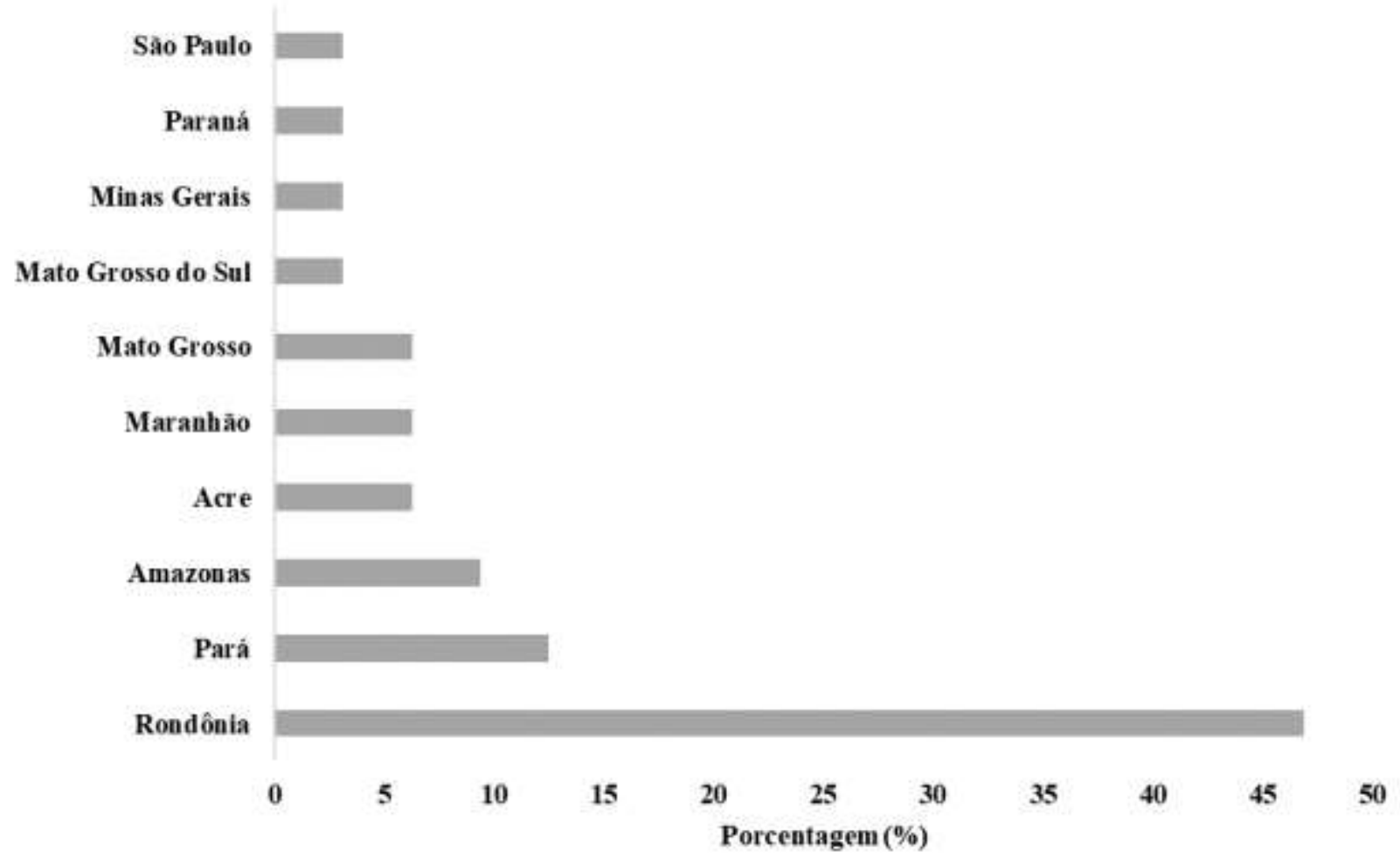

Fonte: Dados da pesquisa.

Ao considerar que os assentados são oriundos de diferentes regiões, buscou-se compreender o motivo de mudança para o assentamento. As razões foram distribuídas nas seguintes categorias:

Relação com a terra: tranquilidade da área rural (15,63\%); acompanhar o marido $(12,50 \%)$; gosto pela agricultura $(6,25 \%)$; pais $(6,25 \%)$; busca por terra para morar (6,25\%); a educação escolar dos filhos $(3,13 \%)$; pai mora no assentamento e bem-estar (3,13\%); filho (3,13\%); devido à questão de gostar do assentamento (3,13\%); gosto pela agricultura e acompanhar o marido $(3,13 \%)$, conforme descrito pelos entrevistados:

"Na cidade, os filhos se envolvem com coisa errada." (Residente feminino, 42 anos).

"Por causa do meu pai, melhor para se viver, melhor do que na cidade." (Residente masculino, 35 anos).

"Meu filho quis morar no assentamento." (Residente feminino, 65 anos).

"Eu gosto do assentamento." (Residente masculino, 54 anos).

"Gosto de agricultura desde criança e por causa do esposo." (Residente feminino, 52 anos).

Relação com o trabalho: ganho de lote para morar e trabalhar $(15,63 \%)$; busca por trabalho $(9,38 \%)$; os fatos de o irmão morar no assentamento e ter vontade de trabalhar (3,13\%); pai reside no PA São Francisco e emprego na prefeitura de 
Canutama (3,13\%); criação no sítio e falta de emprego, essa decorrente do baixo nível de escolaridade (3,13\%); enfermidade e aptidão em trabalhar na roça $(3,13 \%)$. Observaram-se determinados relatos, como:

"Porque теи irmão mora no assentamento e queria trabalhar no local." (Residente masculino, 59 anos).

"Por causa de separação, meu pai mora aqui e trabalho na prefeitura." (Residente feminino, 45 anos).

"Fui criado no sítio e, também, falta de profissão para quem não tem estudo." (Residente masculino, 50 anos).

"Estava doente e queria trabalhar na roça." (Residente masculino, 47 anos).

Mediante os resultados supracitados, o êxodo urbano na procura por tranquilidade que, muitas vezes, não ocorre nas cidades, bem como a busca por trabalho e moradia, considerando a taxa de desemprego que se observa no meio urbano, foram as razões para a ida ao assentamento que obtiveram destaque. Apesar do perfil preponderante na maior parcela das áreas rurais brasileiras estar relacionado ao patrimônio familiar, em muitas regiões rurais do Brasil, a população apresenta hoje uma característica social dessemelhante, predominando a saída de pessoas das cidades para a instalação na zona rural (Gomes et al., 2018a).

No que diz respeito às características econômicas (Tabela 4), as principais fontes de renda dos sujeitos da pesquisa variaram, obtendo-se 50 registros. Destacou-se a produção e venda agrícola, especialmente, das seguintes culturas: macaxeira (Manihot utilissima Pohl.), banana (Musa sp.), abacaxi (Ananas comosus (L.) Merr.), cupuaçu (Theobroma grandiflorum (Willd. ex Spreng.) Schum.), café (Coffea arabica L.), pupunha (Bactris gasipaes Kunth.), guaraná (Paullinia cupana Kunth.), urucum (Bixa orellana L.), milho (Zea mays L.), açaí (Euterpe oleracea Mart.) e pimenta-do-reino (Piper nigrum L.).

Embora a atividade agrícola apresente predomínio com relação à principal fonte de renda, ocorre a complementação de renda com a aposentadoria, auxílios do governo e outros serviços. Tal fato é semelhante ao que foi constatado por Bastos et al. (2018), em que a agricultura é considerada como base econômica, na qual a maior parcela é destinada ao consumo familiar, em um assentamento rural no Piauí, cujo complemento é composto por benefícios do Governo, como Bolsa Família e/ou aposentadoria.

Constatou-se que $38 \%$ do total de entrevistados recebem somente um salário mínimo. Similarmente, Oliveira et al. (2018) verificaram que a renda mensal de 47,70\% das famílias da comunidade de Bom Jesus, Imperatriz - MA, é de um salário mínimo. Já na pesquisa de Leandro et al. (2017), grande parte dos entrevistados possui renda inferior a um salário mínimo. 
Tabela 4. Características econômicas observadas nas entrevistas.

\begin{tabular}{cc}
\hline Características & $\%$ \\
\hline Principais fontes de renda & 2 \\
Aluguel & 18 \\
Aposentadoria & 2 \\
Auxílio do INSS & 4 \\
Bolsa Família & 10 \\
Criação e venda de animais & 4 \\
Não possui fonte de renda & 6 \\
Pensão & 4 \\
Pequeno comércio & 28 \\
Produção e venda agrícola & 8 \\
Salário & 8 \\
Serviços prestados & 6 \\
Venda de doces & \\
Renda mensal (salário mínimo) & 34 \\
$>1$ & 38 \\
1 & 16 \\
2 & 3 \\
3 & 3 \\
Nenhum & 3 \\
Varia & 3 \\
\hline
\end{tabular}

Fonte: Dados da pesquisa.

A ausência de investimentos na produção agrícola, resultando em pequena produtividade, pode culminar em baixas condições financeiras de grande parte dos entrevistados (Araújo, 2017). A inexistência de políticas públicas para melhor produção e venda de produtos agrícolas compromete a renda da maior parte dos agricultores, culminando na dependência dos auxílios governamentais. Alguns entrevistados por possuírem baixa renda salarial não realizam a compra de medicamentos sintéticos devido ao seu alto custo. A maior parte (41\%) do total de plantas citadas é referente aos que possuem somente um salário mínimo.

Para Spanholi e Barreto (2018), o nível de conhecimento a respeito de espécies da flora local e sua utilização também podem ser explicados pela renda, visto que as famílias com menores condições financeiras possuem maior dependência de plantas, objetivando seu sustento. Na visão dos autores, à medida que a renda da família for baixa, o interesse dela em plantar ou realizar a colheita de vegetais para satisfazer suas necessidades medicinais e alimentícias será maior.

O número de moradores por residência varia, prevalecendo duas pessoas por casa (37,50\%), posteriormente, três $(18,75 \%)$, quatro pessoas $(18,75 \%)$, uma pessoa $(12,50 \%)$, cinco pessoas $(9,38 \%)$ e sete pessoas, com $3,13 \%$ do total de entrevistados. Desse modo, observou-se que na maioria das residências se encontra somente o casal, coincidindo com o resultado encontrado por Gomes et al. (2018a), em que na maior parte dos quintais, estava apenas o casal na casa, prevalecendo idosos, e, em determinados casos, os dois não tinham filhos.

\section{Considerações Finais}

Ao ser traçado o perfil socioeconômico e observar maior saber por parte dos residentes mais velhos e mulheres, as quais destacam-se no uso e manutenção dos quintais, foi possível inferir o importante papel desses atores sociais na conservação e transmissão de conhecimentos locais, inclusive, para a inserção e funcionamento de uma Farmácia Viva acessível a todos no assentamento, a fim de ocasionar o autoconsumo e, até mesmo, geração e economia de renda. 
Mesmo com baixas condições financeiras, decorrente, por exemplo, da ineficiência do apoio à produção e comercialização de produtos agrícolas, baixo nível de escolaridade e de serem oriundos de outras regiões, os entrevistados buscam cultivar plantas medicinais em seus quintais, segundo seus saberes, experiências e características físicas da região.

Além disso, constatou-se o uso predominante de adubo orgânico, contribuindo para a produção orgânica e consumo sustentável, sem prejuízos ao meio ambiente. Não obstante, é necessário atentar-se para a legitimidade, acesso e atuação efetiva de políticas públicas, bem como à disponibilização e eficiência de assistência técnica, uma vez que no local de estudo foram verificadas algumas deficiências em relação ao cultivo adequado de espécies vegetais medicinais. Na região amazônica, o conhecimento sobre os elementos da natureza e sua dinâmica é utilizado como recurso de sobrevivência, podendo ser visto como uma nova forma de encarar a relação do homem com a natureza, aplicando estratégias de uso sustentável em políticas públicas de saúde.

As famílias no local de estudo procuram, por meio da agricultura familiar, obter uma forma de subsistência e segurança alimentar e, por causa de carências socioeconômicas, encontram na medicina popular acerca de plantas com finalidade terapêutica uma alternativa para a promoção de seu bem-estar e melhor qualidade de vida, devendo estar atentas para a utilização e dosagem corretas.

É relevante, nesse viés, tanto por parte do poder público e sociedade, e a partir de aspectos apontados nesta pesquisa, um olhar integrativo, indubitável, construtivo, propício e constante para a questão da agricultura familiar, tal como à inclusão e fortalecimento do desenvolvimento rural sustentável. Baseando-se, impreterivelmente, no diagnóstico da relação socioeconômica e ambiental entre os assentados e o uso da biota amazônica, como vegetais com caráter terapêutico.

Também é importante destacar a realização de outros trabalhos em assentamentos rurais na Amazônia brasileira, no que diz respeito à caracterização e investimentos em quintais, além da ação de políticas públicas, em virtude de especificidades físicas, sociais e econômicas na região, onde se encontra uma grande diversidade de plantas que fornecem benefícios à população local. A flora medicinal, inclusive, pode ser afetada negativamente pelo desmatamento e queimadas fora de controle, sendo necessária a busca ininterrupta por práticas conservacionistas.

\section{Referências}

Albuquerque, U. P., Lucena, R. F. P., \& Lins Neto, E. M. F. (2010). Seleção dos participantes da pesquisa. In: Albuquerque, U. P., Lucena, R. F. P., \& Cunha, L. V. F. C. (Orgs.). Métodos e técnicas na pesquisa etnobiológica e etnoecológica (pp. 21-37). NUPEEA.

Almeida, L. S., \& Gama, J. R. V. (2014). Quintais agroflorestais: estrutura, composição florística e aspectos socioambientais em área de assentamento rural na Amazônia brasileira. Ciência Florestal, 24(4), 1041-1053.

Amaral, C. N., \& Guarim Neto, G. (2008). Os quintais como espaços de conservação e cultivo de alimentos: um estudo na cidade de Rosário Oeste (Mato Grosso, Brasil). Boletim do Museu Paraense Emílio Goeldi, 3(3), 329-341.

Araújo, J. S. (2017). Percepção agroecológica dos agricultores familiares do assentamento "São Francisco" no município de Canutama - AM. Dissertação (Mestrado em Ciências Ambientais) - Universidade Federal do Amazonas, Instituto de Educação, Agricultura e Ambiente, Humaitá.

Azambuja, T. C., Chagas, J. C. N., \& Ferreira, F. D. (2018). Teçume-Igapó: mulheres unidas pela Amazônia. Inclusão Social, $12,172-182$.

Bailey, K. (1994). Methods of social research. The Free Press.

Barbosa, E. L. (2019). Políticas públicas no campo no assentamento São Francisco no sul do Amazonas. Dissertação (Mestrado em Ciências Ambientais) Universidade Federal do Amazonas, Instituto de Educação, Agricultura e Ambiente, Humaitá.

Barreto, H. C. A., Carvalho, D. S., \& Lima, J. P. S. (2020). Manejo e uso de plantas medicinais na comunidade Nossa Senhora do Livramento, Amazonas, Brasil. Educação Ambiental em Ação, 18(70), 1-20.

Bastos, E. M., Chaves e Silva, M. E., Vieira, F. J., \& Barros, R. F. M. (2018). Conhecimento botânico local em uma área de assentamento rural no Piauí, Nordeste do Brasil. Gaia Scientia, 12(2), 12-33. https://doi.org/10.22478/ufpb.1981-1268.2018v12n2.34918.

Carvalho, S. P., Ferreira, G. A., Marin, J. O. B., Vargas, F., Belo, A. F. C. F., \& Mendonça, D. C. (2009). Reforma Agrária: a realidade de um assentamento rural. CAMPO-TERRITÓRIO: Revista de Geografia Agrária, 4(8), 67-97. 
Carvalho, D. S. (2019). Preservação dos Saberes Tradicionais de Plantas Medicinais no Assentamento São Francisco, Canutama, Amazonas. Dissertação (Mestrado em Ciências Ambientais) - Universidade Federal do Amazonas, Instituto de Educação, Agricultura e Ambiente, Humaitá.

Cunha, S. A., \& Bortolotto, I. M. (2011). Etnobotânica de plantas medicinais no assentamento Monjolinho, município de Anastácio, Mato Grosso do Sul, Brasil. Acta Botanica Brasilica, 25(3), 685-698. https://doi.org/10.1590/S0102-33062011000300022.

Elisabetsky, E. (2002). Etnofarmacologia como ferramenta na busca de substâncias ativas. In: Simões, C. M. O., Schenkel, E. P., Gosmann, G., Mello, J. C. P., Mentz, L. A., \& Petrovick, P. R. (Orgs.). Farmacognosia: da planta ao medicamento (pp. 91-103). Ed. da UFRGS/Ed. da UFSC.

EMBRAPA - Empresa Brasileira de Pesquisa Agropecuária. (2013). Sistema Brasileiro de Classificação de Solos (3a ed). Embrapa Solos.

Ferreira, L. B., Rodrigues, M. O., \& Costa, J. M. (2016). Etnobotânica das plantas medicinais cultivadas nos quintais do bairro de Algodoal em Abaetetuba/PA. Revista Fitos, 10(3), 220-372.

Finatto, J., Altmayer, T., Martini, M. C., Rodrigues, M., Basso, V., \& Hoehne, L. (2013). A importância da utilização da adubação orgânica na agricultura. Destaques Acadêmicos, 5(4), 85-93, 2013.

Flor, A. S. S. O., \& Barbosa, W. L. R. (2015). Sabedoria popular no uso de plantas medicinais pelos moradores do bairro do Sossego no Distrito de Marudá PA. Revista Brasileira de Plantas Medicinais, 17(4), 757-768. http://dx.doi.org/10.1590/1983-084X/14_064.

Freitas, A. V. L., Coelho, M. F. B., Maia, S. S. S., \& Azevedo, R. A. B. (2012). Plantas medicinais: um estudo etnobotânico nos quintais do Sítio Cruz, São Miguel, Rio Grande do Norte, Brasil. Revista Brasileira de Biociências, 10, 48-59.

Gomes, K. B. P., Martins, R. C. C., Dias, C. A., \& Matos, J. M. M. (2018a). Quintais agroflorestais: características agrossociais sob a ótica da agricultura familiar. Revista Ibero-Americana de Ciências Ambientais, 9(4), 111-124. https://doi.org/10.6008/CBPC2179-6858.2018.004.0009.

Gomes, M. C., Nogueira, A. C. F., \& Costa, F. S. (2018b). Assistência técnica e extensão rural em comunidades rurais do sul do Amazonas. Novos Cadernos NAEA, 21(2), 193-211.

Gomes, N. S., \& Lima, J. P. S. (2017). Uso e comercialização de plantas medicinais em Humaitá, Amazonas. Revista Brasileira de Agroecologia, 12(1), 1931.

Gomes, T. P. S., Ferrante, V. L. S. B., \& Whitaker, D. C. A. (2019). Co-educação, reconhecimento e saberes tradicionais: um estudo com mulheres assentadas em Araraquara - SP. Retratos de Assentamentos, 22(2), 308-326. https://doi.org/10.25059/2527-2594/retratosdeassentamentos/2019.v22i2.388.

IBGE - Instituto Brasileiro de Geografia e Estatística. (2017a). Canutama. https://cidades.ibge.gov.br/brasil/am/canutama/panorama.

IBGE - Instituto Brasileiro de Geografia e Estatística. (2017b). Canutama - Censo Agropecuário. https://cidades.ibge.gov.br/brasil/am/can utama/pesquisa/24/76693.

IDAM - Instituto de Desenvolvimento Agropecuário e Florestal Sustentável do Estado do Amazonas. (2013). Canutama. http://www.idam.am. gov.br/municipio/canutama/.

INCRA - Instituto Nacional de Colonização e Reforma Agrária. (2017). INCRA nos Estados - Informações gerais sobre os assentamentos da Reforma Agrária. http://painel.incra.gov.br/sistemas/index.php.

INCRA - Instituto Nacional de Colonização e Reforma Agrária. (2020). Projetos de Reforma Agrária conforme fases de implementação. http://www.incra.gov.br/media/docs/reforma-agraria/assentamentos-geral.pdf.

Leal, L. S. G., Filipak, A., Duval, H. C., Ferraz, J. M. G., \& Ferrante, V. L. S. B. (2020). Quintais produtivos como espaços da agroecologia desenvolvidos por mulheres rurais. Perspectivas em Diálogo: Revista de Educação e Sociedade, 7(14), 31-54.

Leandro, Y. A. S., Jardim, I. N., \& Gavilanes, M. L. (2017). Uso de plantas medicinais nos cuidados de saúde dos moradores de assentamento no município de Anapu, Pará, Brasil. Biodiversidade, 16(2), 30-44.

Lima, J. M. S., Pinheiro, C. C. S., \& Silva, M. F. (2015). Etnoconhecimento de plantas odontálgicas usadas no assentamento Tarumã-Mirim, Manaus, Amazonas. Scientia Amazonia, 4(2), 25-35.

Lima, K. N., \& Pontes Filho, R. P. (2020). Agricultura familiar no contexto socioambiental amazônico. Revista Direitos Sociais e Políticas Públicas (UNIFAFIBE), 8, 283-306.

Lima, R. A., Xavier, R. A. T., \& Cavalcante, F. S. (2020). The importance of the rescue and preservation of medicinal plants in the North Region in the last twenty years. Ciência e Natura, 42(7), 1-9.

Maia, S. G. C., \& Bombarda Sobrinho, S. (2019). Análise etnobotânica da estrutura de quintais na fronteira Brasil/Paraguai. Ethnoscientia, 4, 1-17.

Marconi, M. A., \& Lakatos, E. M. (1996). Técnicas de pesquisa: planejamento e execução de pesquisas, amostragens e técnicas de pesquisas, elaboração e interpretação de dados (3. ed.). São Paulo: Atlas.

Medeiros, M. S., Augusto, L. G. S., Barca, S., Sacramento, D. S., Santiago Neta, I. S., Gonçalves, I. C., \& Costa, A. M. (2018). A saúde no contexto de uma reserva de desenvolvimento sustentável: o caso de Mamirauá, na Amazônia Brasileira. Saúde e Sociedade, 27(1), 128-148. https://doi.org/10.1590/S010412902018170514 .

Meirelles, F. A., Carrero, G. C., Fernandes Neto, J. G., Cenamo, M. C., \& Guarido, P. C. P. (2018). Análise ambiental e socioeconômica dos municípios sob influência da rodovia BR-319. Manaus: IDESAM. https://idesam.org/publicacao/analise-municipios-br319.pdf. 
Messias, M. C. T. B., Menegatto, M. F., Prado, A. C. C., Santos, B. R., \& Guimarães, M. F. M. (2015). Uso popular de plantas medicinais e perfil socioeconômico dos usuários: um estudo em área urbana em Ouro Preto, MG, Brasil. Revista Brasileira de Plantas Medicinais, 17, 76-104. http://dx.doi.org/10.1590/1983-084X/12_139.

Moraes, M. D., \& Sant'ana, A. L. (2016). Características socioeconômicas do assentamento Banco da Terra, Nova Xavantina (MT): uma análise sob a ótica da adoção ou construção de conhecimentos. Revista de Economia e Sociologia Rural, 53(4), 589-606. http://dx.doi.org/10.1590/1234-56781806-9479005304002.

Nogueira, E. M. L., Mascarenhas, S. A. N., Mendonça, M. F., Morais, L. M., \& Costa, J. I. (2017). Recursos Naturais: Conflitos no uso dos recursos no sul do Amazonas e Alto Solimões, desafios da cidadania na Amazônia brasileira. In: Mascarenhas, S. A. N., \& Araújo, J. N. (Coords.). Desafios para o exercício da cidadania, qualidade de vida e inclusão socioeconômica na Amazônia (pp. 327-346). São Paulo: Loyola.

NUPEAS - Núcleo de Pesquisa e Extensão em Ambiente, Socioeconomia e Agroecologia. (2016). Instalação de sistema de irrigação na Unidade Agrícola Participativa/UAP do PA São Francisco em Canutama/AM. http://nupeas.blogspot.com.br/2016/03/instalacao-de-sistema-de-irrigacao-na.html.

Oliveira, R. A., Silva, R. V., Neves, V. L. D., Nascimento, I. O., Oliveira, F. S., Nunes, S. E. A., \& Belfort, M. G. S. (2018). Perfil etnobotânico de plantas utilizadas como medicinais na comunidade de Bom Jesus, município de Imperatriz - MA. Educação Ambiental em Ação, 17(66), 1-10.

Pereira, S. C. B., Jardim, I. N., Freitas, A. D. D., \& Paraense, V. C. (2018). Levantamento etnobotânico de quintais agroflorestais em Agrovila no município de Altamira, Pará. Revista Verde de Agroecologia e Desenvolvimento Sustentável, 13(2), 200-207. http://dx.doi.org/10.18378/rvads.v13i2.5292.

Pessoa Junior, E. S. F., Souza, W. B., Souza, K. S., Pio, M. C. S., \& Santana, G. P. (2012). Terra preta de índio na região amazônica. Scientia Amazonia, 1, 18 .

Prodanov, C. C., \& Freitas, E. C. (2013). Metodologia do Trabalho Científico: Métodos e técnicas da pesquisa e do trabalho acadêmico (2. ed.). Novo Hamburgo: Feevale.

Rayol, B. P., \& Miranda, I. S. (2019). Quintais agroflorestais na Amazônia Central: caracterização, importância social e agrobiodiversidade. Ciência Florestal, 29(4), 1614-1629. https://doi.org/10.5902/1980509829853.

Ricardo, L. M. (2011). O uso de plantas medicinais na medicina popular praticada em assentamentos do MST do estado do Rio de Janeiro: uma contribuição para o SUS. Dissertação (Mestrado em Ciências na área de Saúde Pública) - Escola Nacional de Saúde Pública Sergio Arouca, Rio de Janeiro.

Santos, L. S. N., Salles, M. G. F., Pinto, C. M., Pinto, O. R. O., \& Rodrigues, I. C. S. (2018). O saber etnobotânico sobre plantas medicinais na comunidade da Brenha, Redenção, CE. Agrarian Academy - Centro Científico Conhecer, 5(9), 409-421.

Santos, E. G., Santos, S. S., Gonçalves, V. N., Souza, B. I., \& Lucena, R. F. P. (2019). Utilização de recursos vegetais em áreas de quintais em uma comunidade rural localizada no entorno do Parque Nacional de Sete Cidades, Piaú, Nordeste do Brasil. Revista Brasileira de Gestão Ambiental e Sustentabilidade, 6(13), 365-383. https://doi.org/10.21438/rbgas.061308.

Schiavo, M.; Schwambach, K. H., \& Colet, C. F. (2017). Conhecimento sobre plantas medicinais e fitoterápicos de agentes comunitários de saúde de Ijuí/RS. Revista de Pesquisa Cuidado é Fundamental Online, 9(1), 57-63. https://doi.org/10.9789/2175-5361.2017.v9i1.57-63.

Silva, O. B., Rocha, D. M., \& Pereira, N. V. (2020). O saber tradicional e uso de plantas medicinais por moradores do assentamento Padre Ezequiel em Mirante da Serra - RO, Brasil. Biodiversidade, 19, 77-96.

Souza, A. L., Silva, V. V., \& Silva, T. A. (2018). Políticas públicas e suas influências ambientais em assentamentos rurais no sul do estado do Amazonas. Educação Ambiental em Ação, 16(63), 1-11.

Spanholi, M. L., \& Barreto, M. R. (2018). Uso popular de recursos vegetais e perfil socioeconômico de moradores de comunidades rurais de Sinop, Mato Grosso, Brasil. Gaia Scientia, 12, 108-127. https://doi.org/10.22478/ufpb.1981-1268.2018v12n1.33130.

Vásquez, S. P. F., Mendonça, M. S., \& Noda, S. N. (2014). Etnobotânica de plantas medicinais em comunidades ribeirinhas do município de Manacapuru, Amazonas, Brasil. Acta Amazonica, 44(4), 457-472. https://doi.org/10.1590/1809-4392201400423.

Vieira, T. A., Rosa, L. S., \& Santos, M. M. L. S. (2012). Agrobiodiversidade de quintais agroflorestais no município de Bonito, estado do Pará. Revista de Ciências Agrárias - Amazonian Journal of Agricultural and Environmental Sciences, 55(3), 159-166. http://dx.doi.org/10.4322/rca.2012.054. 